\title{
EVALUATION OF OCULAR FILMS OF OFLOXACIN FOR ANTIBACTERIAL ACTIVITY
}

\author{
ARUN KUMAR ${ }^{1}$, BRIJESH KUMAR TIWARI ${ }^{2}$, SOKINDRA KUMAR ${ }^{3}$ \\ ${ }^{1}$ Sanskar College of Pharmacy and Research, Ghaziabad, Uttar Pradesh, India, ²Department of Pharmacy, Dr. B. R. Ambedkar University, \\ Agra, Uttar Pradesh, India, ${ }^{3}$ R. V. Northland Institute, Greater Noida, Uttar Pradesh, India \\ Email: sagarlight@gmail.com
}

Received: 08 May 2018, Revised and Accepted: 15 Oct 2018

\begin{abstract}
Objective: The current study emphasizes on the treatment of ocular infection with objectives of reducing the frequency of administration, obtaining controlled release and greater therapeutic efficacy of the drug (ofloxacin) using ocular films.

Methods: Ocular films were designed by solvent evaporation method containing a different combination of polymers. The folding endurance (mechanical strength) was determined by the number of folds at a specific single place required to break the film into two parts. Thickness was measured using screw gauze. The surface $\mathrm{pH}$ was done by $\mathrm{pH}$ paper. The percentage moisture absorption was carried out by placing the ocular films in a desiccator containing ammonium chloride. Percentage moisture loss was carried out by placing the ocular films in the desiccator containing anhydrous calcium chloride. in vitro drug release study were carried by using a modified version of franz diffusion cell. Stability study were carried using stability chambers as per ICH guidelines. The antibacterial activity was performed by using male albino rabbits.

Results: The thickness and folding endurance of the films were in the range of $44 \pm 1.1$ to $92 \pm 1.8$ and $4.5 \pm 0.6$ to $6.8 \pm 0.3$, respectively for different formulations. Surface $\mathrm{pH}$ was evaluated in the range of 6.6 to 7.2. Percentage moisture absorption and percentage moisture loss were evaluated in the range of $1.17 \pm 1.1$ to $6.72 \pm 1.5$ and $0.58 \pm 0.9$ to $1.23 \pm 0.9$ respectively. Microbial growth was not observed in any formulation during sterility testing. The drug release for different batch codes PAH, PBE, PCP, PDC, PEEH, and PFEC was found to be 96.2, 56.9, 93.4, 94.5, 98.4 and 95.9 \% respectively up to $12 \mathrm{~h}$. Ocular films of batch code PEEH was optimized for maximum drug release (98.4\%). The antibacterial effect was noted periodically ( 01 to $05 \mathrm{~d}$ ) after administration of sterile formulation in the treated eyes vs. control eyes of each rabbit. The optimized batch PEEH of ocular films reduced the infection and redness completely within $3 \mathrm{~d}$ in a single dose.
\end{abstract}

Conclusion: The optimized formulation would be able to offer benefits such as increased residence time, prolonged drug release, reduced frequency of administration and improved patient compliance with complete removal of inflammation and redness from the cul-de-sac.

Keywords: Ofloxacin, Ocular films, Solvent evaporation method

(C) 2018 The Authors. Published by Innovare Academic Sciences Pvt Ltd. This is an open access article under the CC BY license (http://creativecommons.org/licenses/by/4.0/) DOI: http://dx.doi.org/10.22159/ijap.2018v10i6.27188

\section{INTRODUCTION}

Ophthalmic liquid preparations are insufficient due to poor bioavailability of the drug, caused by fast lachrymal secretion and poor patient compliance [1]. The unique anatomy and physiology of the eye renders it a highly protected and sensitive organ, and the unique structure restricts drug entry at the target site of action. Conventional drug delivery systems including eye drops, suspensions, and ointments for the treatment of various infections in the cul-de-sac are frequently used, but they cannot be considered optimal because most topically instilled drugs do not offer adequate bioavailability due to the wash off of the drugs from the eye through lacrimation and tear dilution [2].

In addition, the human cornea composed of epithelium, substantia propria and endothelium hinders drug entry; consequently, less than $5 \%$ of the administered drug enters into the eye. Alternative approaches (ocular inserts/films, corneal shield, sol to gel system etc.) are continuously sought to facilitate significant drug absorption into the eye $[3,4]$. In this ocular research films of an antibacterial drug (ofloxacin) was developed and evaluated for antibacterial response with a programmed rate for a longer period by increasing precorneal residence time [5].

The permeability of drugs through the polymeric films is dependent on the characteristics of the polymer, the casting solvent, and the plasticizers used. Plasticizers (phthalate esters, phosphate esters, fatty acid esters, and glycol derivatives) are very useful in the preparation of polymeric ocular films to reduce the brittleness, to impart flexibility, to increase strength, and also to improve adhesiveness of the films with surfaces or membranes [6].

To accomplish the aim of this research the predicted batches of ocular films of different concentration of polymer combinations were optimized through the factorial design study and the final batches were selected and developed containing hydroxyl propyl methyl cellulose (HPMC K100M), polyvinylpyrrolidone (PVP) and ethyl cellulose in the concentration of $0.5 \%, 0.5 \%$ and $1.0 \%$ respectively with polyethylene glycol (PEG 400) 10\% w/w as plasticizer. Optimized ocular films were evaluated with various parameters such as folding endurance, the thickness of films, surface $\mathrm{pH}$, percent moisture absorption, percent moisture loss, percent drug release, stability study, sterility testing and in vivo study $[7,8]$.

\section{MATERIALS AND METHODS}

\section{Materials}

Baxil Pharma Pvt. Ltd., Haridwar, India provided a gift sample of Ofloxacin while all the polymers of analytical grade were purchased from different suppliers of India like Hydroxyl Propyl Methyl Cellulose (HPMC K100M) from Loba Chemie Pvt. Ltd.-Mumbai, Polyvinylpyrrolidone (PVP) and Ethyl Cellulose from Qualikems fine chem. Pvt Ltd.-Delhi. Polyethylene Glycol (PEG 400) was purchased from Antares Chem. Pvt Ltd.-Mumbai and Arachidonic acid was purchased from Hi-Media Labs Pvt. Ltd., Mumbai. Microbial culture (Staphylococcus aureus) was purchased from Institute of Microbial Technology (IMTECH), Chandigarh, 06 male Albino rabbits, were provided by research place (animal house of $\mathrm{R} \mathrm{V}$ Northland Institute) after IAEC protocol approval (Approval No.1149/PO/ac/07/CPCSEA) through CPCSEA.

\section{Method}

Various combinations were designed for different batches of ocular films as per factorial design study with $0.5 \% \mathrm{w} / \mathrm{v}$ concentration by solvent evaporation method containing a different combination of polymers such as hydroxyl propyl methyl cellulose (HPMC K100M), ethyl cellulose, carbopol 934 and polyvinylpyrrolidone (PVP). The optimized concentration of selected polymers were homogenized to 
make a clear solution. When the clear solution was prepared, $25 \mathrm{ml}$ solution for five films was pipetted out, and the drug was added to the solution and homogenized with the aid of stirring. The solution so obtained was poured onto the glass ring placed over the prelubricated petri plates. One glass ring consumed $5 \mathrm{ml}$ of the drug solution. An inverted funnel was placed over the petri plate to allow slow evaporation. The open end of the funnel was plugged with cotton wool. The whole assembly was left undisturbed till the films dried. After the complete drying, the film rings were lifted from the petri plates, and the suitable size was cut from the help of die. Different parameters have been evaluated for optimized ocular films; folding endurance, thickness, surface $\mathrm{pH}$, percentage moisture absorption, percentage moisture loss, in vitro drug release study, stability study and antibacterial activity were performed with male albino rabbits.

\section{Physicochemical characterization of ocular films}

The ocular films of ofloxacin were evaluated for physicochemical characteristics such as folding endurance, thickness, surface $\mathrm{pH}, \%$ moisture absorption, \% moisture loss, stability study and \% drug release. The folding endurance of ocular films was determined by the number of folds at a specific single place required to break the film into two parts. The thickness of the recovered films was measured using screw gauze [9]. After performing the initial settings the film was placed on the anvil such that area where the thickness is to be measured lies. The screw was gently tightened on to the specimen and reading of the gauze was noted to get the thickness of the film. The surface $\mathrm{pH}$ determination of the film was done by allowing them to swell by placing 2 drops of distilled water over it. After this the swollen film was taken and $\mathrm{pH}$ was determined using $\mathrm{pH}$ paper on the surface of the film [10].

The percentage moisture absorption test was carried out to check physical stability or integrity of the ocular films. Ocular films were weighed and placed in a desiccator containing $100 \mathrm{ml}$ of saturated solution of ammonium chloride. After $3 \mathrm{~d}$ the ocular films were taken out and reweighed. The percentage moisture absorption was calculated using the formula [11]:

$$
\% \text { moisture absorption }=\text { final weight }-\frac{\text { initial weight }}{\text { initial weight }} \times 100
$$

Percentage moisture loss was carried out to check the integrity of the film at dry condition. Ocular films were weighed and kept in the desiccators containing anhydrous calcium chloride. After $3 \mathrm{~d}$ the ocular films were taken out and reweighed, the percentage moisture loss was calculated using the formula [12]:

$$
\% \text { moisture loss }=\text { initial weight }-\frac{\text { final weight }}{\text { initial weight }} \times 100
$$

\section{In vitro drug release study}

The inserts were placed on a modified version of Franz diffusion cell using cellophane membrane in contact with isotonic phosphate buffer pH 7.4 kept at $37 \pm 1^{\circ} \mathrm{C}$ with constant stirring of $50 \mathrm{rpm} .1 \mathrm{ml}$ Sample was withdrawn at different time intervals analyzed for drug content spectrophotometrically (Shimadzu UV 1700) at $294 \mathrm{~nm} \mathrm{[13,}$ 14].

\section{Stability study of optimized batch of ocular film}

Stability studies were carried out on batch code PEEH, according to ICH guidelines by storing replicates of ocular films (packaged in aluminium foil) for a period of $0,30,90$ and $180 \mathrm{~d}$ with a relative humidity $75 \% \pm 5 \%$ at a temperature $40^{\circ} \pm 2{ }^{\circ} \mathrm{C}$ and $180 \mathrm{~d}$ at room temperature using the stability chamber. The sample was collected after 30, 90, $180 \mathrm{~d}$ under accelerated conditions and $180 \mathrm{~d}$ at RT, respectively and evaluated $[15,16]$.

\section{Sterility testing of optimized batch of ocular film}

Sterility tests were based on the principle that if bacteria of fungi are placed in a medium having moisture and the desired $\mathrm{pH}$ and kept at a favorable temperature, the organism will grow and their presence can be indicated by the growth in originally medium [17]. Optimized batch of ocular films was taken in two different sterile nutrient agar petri dishes. One uninoculated nutrient agar petri dish was taken as a negative control (to test sterility of the medium). A lab isolated culture of Staphylococcus aureus was inoculated in one nutrient agar petri dish served as positive control. Both the petri dishes were incubated at $37{ }^{\circ} \mathrm{C}$ for $24 \mathrm{~h}$. Results were interpreted with positive and negative control petri dishes. The growth of microorganism was observed in positive control and no growth of microorganisms was observed in the negative control test, which confirmed that all the apparatus used for the test were sterile and aseptic conditions were maintained. Now the sample formulation was placed in the negative control test and incubated at same conditions. There was no growth of a microorganism in the samples under test, confirming the sterility of ocular films. These sterile ocular films were considered suitable for in vivo studies [18-20].

\section{Sterilization of optimized batch of ocular film}

These formulations were sterilized separately by exposing both sides to UV radiation for $90 \mathrm{~min}$ in a cabinet under aseptic conditions and were finally packaged in pre-sterilized aluminium foil [21].

\section{In vivo study}

The protocol for in vivo studies in rabbit was designed and approved by institutional animal ethics committee of research place. The rabbits were fed balanced diet pellets and maintained in a temperature-controlled room, at $20{ }^{\circ} \mathrm{C}$ to $24{ }^{\circ} \mathrm{C}$ before the experiment. The antibacterial activity (redness in conjunctiva and zone of inhibition for microbial growth) was carried with all 06 rabbits eyes divided into two groups (left eyes as a positive control group and right eyes as treated group). A microbial culture of Staphylococcus aureus $10 \mu \mathrm{l}$ was instilled into both groups in each rabbit and incubated at room temperature in an aseptic room of microbiology lab for $24 \mathrm{~h}$. The redness and infection in both groups in each rabbit were observed, and treatment was started after $24 \mathrm{~h}$ up to $5 \mathrm{~d}$ with the administration of sterile ocular inserts containing ofloxacin only in treated groups per day.

Redness was scored as follows: $0=$ Normal; $1=$ mild redness; $2=$ moderate redness; and $3=$ fully red conjunctiva. With this test, zone of inhibition was also observed for the treated group. Fresh sterile nutrient agar petri dishes were prepared and incubated for $24 \mathrm{~h}$ with test organism (S. aureus culture) at $37{ }^{\circ} \mathrm{C}$. The fluid tear samples from the treated group were collected at an interval of $2 \mathrm{~h}$ with the help of a sterile swab up to $12 \mathrm{~h}$. These swabs (containing released drug from ocular films) were placed on petri dishes of test organism over $24 \mathrm{~h}$ and the zone of inhibition were calculated separately with the help of Image-J software [22, 24].

\section{RESULTS AND DISCUSSION}

The ocular films of ofloxacin were prepared by a solvent evaporation method using glycerin as a lubricant and characterized on the bases of physicochemical parameters, sterility testing, in vitro and in vivo release studies. All the formulations with each polymer were evaluated for various parameters such as folding endurance, thickness, surface $\mathrm{pH}, \%$ moisture absorption, $\%$ moisture loss, drug release of ofloxacin (table 1). The nature of rate-controlling membrane had influences on the physicochemical characteristics of the ocular films. The plasticizer is the most important component which may affects the mechanical properties of the films by lowering the glass-transition temperature of the polymer.

In this study, polyethylene glycol (PEG-400) at a concentration of $10 \% \mathrm{w} / \mathrm{w}$ of total polymer was selected since it gave sufficiently pliable films to allow for uniform subdivision into films without breaking the film. Ocular films of hydroxyl propyl methyl cellulose (HPMC K100M) with rate-controlling membranes of ethyl cellulose (EC) and polyvinylpyrrolidone (PVP) were flexible and elastic. Thickness and folding endurance were optimum in all batches and the $\%$ cumulative drug release (table 2) was evaluated with all six batches, the batch code PEEH was optimized with a maximum drug release $(98.4 \pm 1.1)$ having surface $\mathrm{pH}(7.2), \%$ moisture absorption $(2.97 \pm 1.1 \mathrm{w} / \mathrm{w})$ and $\%$ moisture loss $(0.58 \pm 0.9 \mathrm{w} / \mathrm{w})$. 
Table 1: in vitro evaluation of optimized batches

\begin{tabular}{llllll}
\hline Batch code & Thickness $(\boldsymbol{\mu m})$ & $\begin{array}{l}\text { Folding endurance } \\
\text { (no. of folds) }\end{array}$ & $\begin{array}{l}\text { Surface pH } \\
\text { \% Moisture } \\
\text { absorption }(\mathbf{w} / \mathbf{w})\end{array}$ & $\begin{array}{l}\text { \% moisture loss } \\
(\mathbf{w} / \mathbf{w})\end{array}$ \\
\hline PAH & $5.6 \pm 0.2$ & $73 \pm 1.2$ & 6.9 & $6.72 \pm 1.5$ & $1.02 \pm 0.8$ \\
PBE & $4.6 \pm 0.1$ & $92 \pm 1.8$ & 7.1 & $1.17 \pm 1.1$ & $0.58 \pm 1.7$ \\
PCP & $6.8 \pm 0.3$ & $47 \pm 0.9$ & 6.6 & $4.88 \pm 1.2$ & $0.98 \pm 1.0$ \\
PDC & $6.3 \pm 0.2$ & $44 \pm 1.1$ & 7.1 & $6.15 \pm 1.6$ & $1.23 \pm 0.9$ \\
PEEH & $4.9 \pm 0.2$ & $82 \pm 1.1$ & 7.2 & $2.97 \pm 1.1$ & $0.58 \pm 0.9$ \\
PFEC & $4.5 \pm 0.6$ & $48 \pm 0.7$ & 7.1 & $3.04 \pm 1.2$ & $96.9 \pm 0.9$ \\
\hline
\end{tabular}

Values are expressed as mean \pm SD $(n=5)$

Table 2: \% cumulative release of optimized batches of ocular films of ofloxacin

\begin{tabular}{|c|c|c|c|c|c|c|}
\hline Time (h) & PAH & PBE & PCP & PDC & PEEH & PFEC \\
\hline 0.5 & 9.14 & 8.06 & 6.03 & 9.10 & 9.70 & 6.00 \\
\hline 1 & 18.07 & 13.36 & 15.02 & 16.10 & 11.09 & 15.76 \\
\hline 1.5 & 27.02 & 19.61 & 25.66 & 23.10 & 28.83 & 22.20 \\
\hline 2 & 34.10 & 24.05 & 39.91 & 33.11 & 34.78 & 32.65 \\
\hline 3 & 45.32 & 25.69 & 45.08 & 40.26 & 47.86 & 45.66 \\
\hline 4 & 50.95 & 32.76 & 48.79 & 55.88 & 55.22 & 48.96 \\
\hline 5 & 65.15 & 37.00 & 61.86 & 64.60 & 59.86 & 58.72 \\
\hline 6 & 73.18 & 42.91 & 74.57 & 72.63 & 67.83 & 73.62 \\
\hline 7 & 80.51 & 45.41 & 75.46 & 77.13 & 81.27 & 76.85 \\
\hline 8 & 83.97 & 48.29 & 83.02 & 85.59 & 88.08 & 85.25 \\
\hline 10 & 90.62 & 53.51 & 88.94 & 92.64 & 94.46 & 91.87 \\
\hline 12 & 96.20 & 56.90 & 93.40 & 94.50 & 98.40 & 95.90 \\
\hline
\end{tabular}

\section{Stability study}

On the bases of physicochemical characteristics and in vitro comparative release study of all six batches, the stability study was performed for batch code PEEH with accelerated study from $0 \mathrm{~d}$ to 6 mo and up to 6 mo with room temperature and the folding endurance, thickness, surface $\mathrm{pH}, \%$ moisture absorption (table 3) and \% drug release (table 4) were further evaluated. From the accelerated stability studies, performed at elevated temperature and humidity revealed that no significant changes were observed in film thickness, folding endurance and surface $\mathrm{pH}$ [25]. Ocular films could be stored safely at study storage conditions. However, storage temperature not in excess of $40{ }^{\circ} \mathrm{C}$ and moisture-proof packing are recommended to ensure the stability of the formulation. Overall the degradation was less than $5 \%$, a tentative shelf-life of more than years may be assigned to the formulations as per the ICH guidelines.

Table 3: stability study of final selected batch PEEH

\begin{tabular}{lllll}
\hline Parameters evaluated & \multicolumn{2}{l}{ Accelerated study } & & Room temp. \\
\cline { 2 - 5 } & $\mathbf{0 ~ d}$ & $\mathbf{3 0 ~ d}$ & $\mathbf{9 0 ~ d}$ & $\mathbf{1 8 0 ~ d}$ \\
\hline Folding endurance & 82 & 81 & 78 & 75 \\
Thickness $(\mu \mathrm{m})$ & 4.9 & 4.9 & 4.9 & 4.8 \\
Surface $\mathrm{pH}$ & 7.2 & 7.2 & 7.2 & 7.3 \\
\% moisture Absorption $(\mathrm{w} / \mathrm{w})$ & 2.97 & 3.09 & 3.18 & 3.33 \\
\% Drug Release & 96.90 & 95.43 & 94.63 & 93.87 \\
\hline
\end{tabular}

Table 4: Release study of final selected batch PEEH

\begin{tabular}{|c|c|c|c|c|c|}
\hline \multirow{3}{*}{$\begin{array}{l}\text { Time } \\
\text { (H) }\end{array}$} & \multicolumn{5}{|c|}{ Drug release } \\
\hline & \multicolumn{3}{|c|}{ Accelerated study } & \multirow{2}{*}{\multicolumn{2}{|c|}{$\begin{array}{l}\text { Room temp. } \\
180 \mathrm{~d}\end{array}$}} \\
\hline & $\mathbf{0 ~ d}$ & $30 \mathrm{~d}$ & $90 \mathrm{~d}$ & & \\
\hline 0.5 & 5.99 & 5.42 & 6.76 & 5.37 & 7.38 \\
\hline 1 & 15.76 & 14.25 & 11.30 & 8.35 & 9.46 \\
\hline 1.5 & 22.20 & 16.98 & 19.35 & 17.22 & 18.92 \\
\hline 2 & 32.65 & 28.86 & 26.88 & 22.04 & 27.73 \\
\hline 3 & 45.66 & 37.46 & 41.38 & 39.56 & 35.41 \\
\hline 4 & 48.96 & 46.52 & 46.78 & 46.73 & 46.76 \\
\hline 5 & 58.72 & 48.32 & 52.93 & 56.25 & 55.39 \\
\hline 6 & 73.62 & 59.13 & 60.10 & 67.63 & 68.19 \\
\hline 7 & 76.85 & 73.53 & 74.86 & 76.84 & 73.45 \\
\hline 8 & 85.25 & 85.59 & 82.08 & 84.58 & 82.12 \\
\hline 10 & 91.87 & 92.64 & 90.14 & 90.35 & 89.61 \\
\hline 12 & 96.90 & 95.43 & 94.63 & 93.87 & 95.89 \\
\hline
\end{tabular}

\section{In vivo study}

Redness in conjunctiva was noted periodically ( 01 to $05 \mathrm{~d}$ ) in both eyes of each animal after administration of predicted sterile formulation in the treated eyes vs. control eyes [26]. One-way ANOVA, followed by Tukey-Kramer multiple comparison test were used for comparison of the means of different groups [27]. There is a 
significant decrease $(\mathrm{P}<0.01$ and $\mathrm{P}<0.001)$ in scores of redness as compared with positive control group. As per the data shows in the (table 5) the predicted batch PEEH of ocular inserts reduced the redness completely up to 4 th day dose.

Table 5: Effect of the anti-bacterial response of predicted batch PEEH (Avg. mean of score with days)

\begin{tabular}{|c|c|c|c|c|c|}
\hline \multirow{2}{*}{ 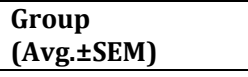 } & \multicolumn{5}{|l|}{ Days } \\
\hline & 1 & 2 & 3 & 4 & 5 \\
\hline Control (Left eye) & $2.666 \pm 0.210$ & $3 \pm 0$ & $2.833 \pm 0.166$ & $3 \pm 0$ & $3 \pm 0$ \\
\hline Treated (Right eye) & $1.833^{* *} \pm 0.166$ & $0.833^{* * *} \pm 0.166$ & $0.333^{* * *} \pm 0.210$ & $0 * * * \pm 0$ & $0 * * * \pm 0$ \\
\hline
\end{tabular}

(** $\mathrm{P}<0.01,{ }^{* * *} \mathrm{P}<0.001$ vs. control group)

\section{Zone of inhibition study}

The bacterial load was noted periodically ( 02 to $12 \mathrm{~h}$ ) in treated eyes of each animal after administration of predicted sterile formulation in the treated eyes vs. control eyes. One-way ANOVA, followed by TukeyKramer multiple comparison tests was used for comparison of the means of different groups. There is a significant difference $(\mathrm{P}<0.001)$ in the diameter area of zone of inhibition as compared with positive control group. The data shows in the (table 6) the samples were withdrawn from the treated groups of a predicted batch of ocular inserts reduced the maximum bacterial load as per standard test (ciprofloxacin CF30 susceptibility test disc were used for in vitro standard test).

Table 6: Effect of the anti-bacterial response of predicted batch PEEH with zone of inhibition (Avg. mean of area in $\mathrm{mm}^{2}$ )

\begin{tabular}{|c|c|c|c|c|c|c|}
\hline \multirow[t]{2}{*}{ 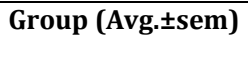 } & \multicolumn{6}{|c|}{ Diameter in $\mathrm{mm}^{2}$ of zone of inhibition with time (hrs) } \\
\hline & 2 & 4 & 6 & 8 & 10 & 12 \\
\hline Treated (Right eye) & $9.5 \pm 0.619$ & $15.5 \pm 1.056$ & $21.666 \pm 0.802$ & $23.166 \pm 0.307$ & $23.5 \pm 0.223$ & $23.833 \pm 0.307$ \\
\hline
\end{tabular}

$\left({ }^{* * *} \mathrm{P}<0.001\right.$ vs. control group)

\section{CONCLUSION}

Ocular films of ofloxacin prepared by a solvent evaporation method using a good film-forming hydrophilic polymer hydroxyl propyl methyl cellulose (HPMC K100M) with a satisfactory rate controlling membranes of ethyl cellulose (EC) and polyvinylpyrrolidone (PVP) included polyethylene glycol (PEG 400) as a plasticizer. Various concentrations were designed with different combinations but the concentration of batch code PEEH was smooth, flexible and transparent. Physicochemical parameters viz folding endurance, thickness, surface $\mathrm{pH}$, percentage moisture absorption, percentage moisture loss, stability study, sterility testing were in optimum range for optimized batch of ocular film. in vitro and in vivo study revealed that the optimized formulation would be able to offer benefits such as increased residence time, prolonged drug release, reduced frequency of administration and improved patient compliance with complete removal of inflammation and redness from the cul-de-sac.

\section{ACKNOWLEDGMENT}

The authors wish to thank R. V. Northland Institute for providing necessary facilities to carry out the research work. Also thanks to Baxil Pharma Pvt. Ltd. for providing a gift sample of the drug.

\section{AUTHORS CONTRIBUTIONS}

All the author have contributed equally

\section{CONFLICT OF INTERESTS}

The authors have no conflict of interest to declare regarding the publication of this paper.

\section{REFERENCES}

1. Halah TS, Hanan JK. Preparation and characterization of econazole nitrate inclusion complex for the ocular delivery system. Int J Appl Pharm 2018;10:175-81.

2. Sreenivas SA, Hiremath SP, Godbole AM. Ofloxacin ocular inserts: design, formulation and evaluation. Iranian J Pharmacol Ther 2006;5:159-62.

3. Peneva PT. Non-steroidal anti-inflammatory drugs for topical ophthalmic administration: contemporary trends. Int J Pharm Pharm Sci 2015;7:13-9.

4. Gaudana R, Jwala J, Boddu SHS, Mitra AK. Recent perspectives in ocular drug delivery. Pharma Res 2009;26:1197-216.

5. Smith SE. Ocular NSAIDs. Therapeutics; 2005. p. 124-7.
6. Chien YW. Novel drug delivery systems (Drugs and the pharmaceutical sciences). New York: Marcel Dekker Inc., Second Edition; 1996.

7. Kothawade SN, Deshpande ST, Lunkad AS, Dighe PA Formulation and in vitro characterization of ketorolac tromethamine ophthalmic inserts. Res J Pharm Dosage Forms Tech 2014;5:311-4.

8. Perry HD, Donnenfeld ED. An update on the use of ophthalmic ketorolac tromethamine 0.4\%. Expert Opinion Pharmacother 2006; 7:99-107.

9. Patel DH, Patel MP, Patel MM. Formulation and evaluation of drug-free ophthalmic films prepared by using various synthetic polymers. Pharmaceutics 2009;1:116-20.

10. Sankar V, Chandrasekaran AK, Durga S, Geetha G, Ravichandra $\mathrm{V}$, Vijayakumar A, et al. Design and evaluation of diclofenac sodium ophthalmic inserts. Acta Pharm Sci 2006;48:5-10.

11. Kumar S, Issarani R, Nagori BP, Ahuja M. Design and evaluation of guar gum based ofloxacin sustained release ocular inserts. Asian J Pharm 2012;6:198-203.

12. Mundada AS, Shrikhande BK. Formulation and evaluation of ciprofloxacin hydrochloride soluble ocular drug insert. Curr Eye Res 2008;33:469-75.

13. Jethava JK, Jethava GK. Design, formulation, and evaluation of novel sustain release bioadhesive in-situ gelling ocular inserts of ketorolac tromethamine. Int J Pharma Inves 2014;4:226-32.

14. Shivhare UD, Chavan MA, Bhusari KP, Mathur VB, Kakade VN. Formulation development and evaluation of controlled release ocular insert. Int J Bio-Pharm Res 2012;3:66-74.

15. Tanwar YS, Patel D, Sisodia SS. In vitro and in vivo evaluation of ocular inserts of ofloxacin. DARU 2007;15:139-45.

16. Mohamed AA, Mohamed al-A. Design and evaluation of ciprofloxacin hydrochloride ocular inserts. Int J Pharm Tech Res 2011;3:1750-63.

17. Shanmugam S, Valarmathi S, Satheesh KS. Sterility testing procedure of ophthalmic ocusert acyclovir used for treating herpes simplex virus. Asian J Pharm Clin Res 2017;10:344-6.

18. Kerur S, Dandgi P, Deshpande P. Controlled release polymeric ocular inserts for delivery of acyclovir. Turkish J Pharm Sci 2010;7:75-90.

19. Jayaprakash S, James CC, Maria NS, Saisivam S, Nagarajan M. Design and evaluation of keterolac tromethamine ocuserts. Indian J Pharm Sci 2000;62:334-8.

20. Rao V, Shyale S. Preparation and evaluation of ocular inserts containing norfloxacin. Turkish J Med Sci 2004;34:239-46. 
21. Pawar PK, Katara R, Majumdar DK. Design and evaluation of moxifloxacin hydrochloride ocular inserts. Acta Pharma 2012;62:93-104.

22. Nageshwara RG, Ramakrishna A. Formulation design and in vitro evaluation of natamycin ocular insert. Int J Pharm Res Biosci 2014;3:687-95.

23. Jervis LP. A summary of recent advances in ocular inserts and implants. J Bioequi Bioavai 2017;9:320-3.

24. Kumar KPS, Bhowmik D, Harish G, Duraivel S, Kumar BP. Ocular inserts: a novel drug delivery system. Pharma Innov J 2013;1:1-16.

25. Kumar A, Mittal A, Kumar S, Singh A, Gupta A. Effect of gelrite concentration on the release through ocular inserts of ciprofloxacin hydrochloride. J Pharm Res 2009;2:487-90.

26. Pandey P, Panwar AK, Dwivedi P, Jain P, Agarwal A, Jain D. Design and evaluation of ocular inserts for controlled drug delivery of acyclovir. Int J Pharm Bio Arch 2011;2:1106-10.

27. Abraham S, Furtado S, Bharath S, Basavaraj BV, Deveshwaran R, Madhavan V. Sustained ophthalmic delivery of ofloxacin from an ion-activated in situ gelling system. Pakistan J Pharm Sci 2009;22:175-9.

28. Balguri SP, Adelli GR, Majumdar S. Topical ophthalmic lipid nanoparticle formulations (SLN, NLC) of indomethacin for delivery to the posterior segment ocular tissues. Eur J Pharm Biopharm 2016;109:224-35.
29. Franca JR. Bimatoprost loaded ocular inserts as sustained release drug delivery systems for glaucoma treatment: in vitro in vivo evaluation. Plos One 2014;9:1-11.

30. Sasaki H. One-side-coated insert as a unique ophthalmic drug delivery system. J Controlled Release 2003;92:241-7.

31. Charoo NA, Kohli K, Ali A, Anwer A. Ophthalmic delivery of ciprofloxacin hydrochloride from different polymer formulations: in vitro and in vivo studies. Drug Dev Ind Pharm 2003;29:215-21.

32. Gupta A, Sharma SK, Ahuja M. In vitro and in vivo evaluation of gellan based ocular inserts of phenylephrine. Acta Pharm Sci 2007;49:55-63.

33. Sultana Y, Aquil M, Ali A. Ocular insert for controlled delivery of pefloxacin mesylate: preparation and evaluation. Acta Pharm 2005;55:305-14.

34. Venkateshwar R, Somashekar S. Preparation and evaluation of ocular inserts containing norfloxacin. Tur J Med Sci 2004;34:239-46.

35. Kaur IP, Kanwar M. Ocular preparations: the formulation approach. Drug Dev Ind Pharm 2002;28:473-93.

36. Upadhyay N, Patidar A, Agrawal S. Development and evaluation of polymeric sustained release levofloxacin ocuserts. Res J Pharm Bio Chem Sci 2011;2:411-21.

37. Mortazavi SA, Jaffariazar Z, Damercheli E. Formulation and in vitro evaluation of ocular ciprofloxacin containing minitablets prepared with different combinations of carbopol 974P and various cellulose derivatives. Iran J Pharm Res 2010;9:107-14. 